University of Wollongong

Research Online

Faculty of Engineering and Information

Faculty of Engineering and Information

Sciences - Papers: Part A

Sciences

2004

Estimation of diffusion coefficients, lateral shear stress, and velocity in open channels with complex geometry

Shu-qing Yang

University of Wollongong, shuqing@uow.edu.au

Jian-Xing Yu

Tianjin University

Yuan-Zhan Wang

Tianjin University

Follow this and additional works at: https://ro.uow.edu.au/eispapers

Part of the Engineering Commons, and the Science and Technology Studies Commons

Research Online is the open access institutional repository for the University of Wollongong. For further information contact the UOW Library: research-pubs@uow.edu.au 


\title{
Estimation of diffusion coefficients, lateral shear stress, and velocity in open channels with complex geometry
}

\author{
Abstract \\ The lateral distributions of depth-averaged apparent shear stress, depth mean velocity, and diffusion \\ coefficients are essential in certain quantitative analysis for sediment transport and environmental \\ studies. An analytical method for the computation of these parameters is presented. A mathematical \\ relationship between these parameters, based on the concept of surplus energy transport through a \\ minimum relative distance developed by Yang and Lim [1997], is established, the depth-averaged \\ apparent shear stress is determined from the boundary shear stress, depth mean velocity is obtained by \\ considering the influence of nonuniform shear velocity and the free surface in 3-D channels, and the \\ diffusion coefficients are linked to the depth-averaged apparent shear and velocity. The theoretical \\ formulations for the distributions of depth-averaged apparent shear stresses, depth mean velocity and \\ diffusion coefficients in trapezoidal and compound channels are presented. Comparisons between the \\ theoretical and the measured lateral distributions of the depth-averaged apparent shear stresses and the \\ depth mean velocities are also presented, and a reasonable agreement is achieved.
}

\section{Keywords}

stress, lateral, geometry, diffusion, estimation, velocity, shear, coefficients, complex, open, channels

\author{
Disciplines \\ Engineering | Science and Technology Studies
}

\section{Publication Details}

Yang, S., Yu, J. \& Wang, Y. (2004). Estimation of diffusion coefficients, lateral shear stress, and velocity in open channels with complex geometry. Water Resources Research, 40 (5), 1-8. 


\title{
Estimation of diffusion coefficients, lateral shear stress, and velocity in open channels with complex geometry
}

\author{
Shu-Qing Yang \\ School of Civil Engineering, Tianjing University, Tianjing, China \\ Maritime Research Center, Nanyang Technological University, Singapore \\ Jian-Xing Yu and Yuan-Zhan Wang \\ School of Civil Engineering, Tianjing University, Tianjing, China
}

Received 31 October 2003; revised 22 February 2004; accepted 23 March 2004; published 15 May 2004.

[1] The lateral distributions of depth-averaged apparent shear stress, depth mean velocity, and diffusion coefficients are essential in certain quantitative analysis for sediment transport and environmental studies. An analytical method for the computation of these parameters is presented. A mathematical relationship between these parameters, based on the concept of surplus energy transport through a minimum relative distance developed by Yang and Lim [1997], is established, the depth-averaged apparent shear stress is determined from the boundary shear stress, depth mean velocity is obtained by considering the influence of nonuniform shear velocity and the free surface in 3-D channels, and the diffusion coefficients are linked to the depth-averaged apparent shear and velocity. The theoretical formulations for the distributions of depth-averaged apparent shear stresses, depth mean velocity and diffusion coefficients in trapezoidal and compound channels are presented. Comparisons between the theoretical and the measured lateral distributions of the depth-averaged apparent shear stresses and the depth mean velocities are also presented, and a reasonable agreement is achieved. INDEX TERMS: 1860 Hydrology: Runoff and streamflow; 1871 Hydrology: Surface water quality; 3379 Meteorology and Atmospheric Dynamics: Turbulence; 4568 Oceanography: Physical: Turbulence, diffusion, and mixing processes; KEYWORDS: open channel flows, boundary shear stress, depth-averaged apparent shear stress, depth-averaged velocity, diffusion coefficient

Citation: Yang, S.-Q., J.-X. Yu, and Y.-Z. Wang (2004), Estimation of diffusion coefficients, lateral shear stress, and velocity in open channels with complex geometry, Water Resour. Res., 40, W05202, doi:10.1029/2003WR002818.

\section{Introduction}

[2] The depth-averaged velocity and shear stress distributions are two important parameters required to study the lateral distribution of cooling water, wastewater or sediment concentration in rivers. The lateral distribution is characterized by the transverse mixing coefficient that plays an important role in both mathematical and physical modeling of pollutant dispersal in rivers. At present, there is no a general method that allows these transverse parameters to be determined from the basic river parameters, such as the channel geometry, energy slope, boundary roughness and its distributions. Even for such idealized situations such as the flow in straight rectangular or compound channel flows, the mechanism that addresses the influence of geometrical, kinematic and dynamical properties on the lateral distributions of depth-averaged velocity and shear stress is not well understood. Therefore a systematical study has to be carried out to investigate the issues at least for straight open channel flows.

[3] Fully developed turbulent flows in a straight uniform channel are particularly important on account of the

Copyright 2004 by the American Geophysical Union. 0043-1397/04/2003WR002818 three-dimensional nature of both the mean flow and the turbulent structure. The lateral distributions of momentum and energy have attracted a certain amount of attentions from those who wish to understand the mechanism of 3-D flows. Keulegan [1938] may be the first one who introduced the idea of flow region division using bisectors of base angles in a 3-D channel. Einstein [1942] also found that the concept of flow region division is also applicable to alluvial channels, however he did not indicate how to determine the division lines. Adachi [1962] suggested that the division lines be determined by equating the velocity from the bottom and side walls at the division lines where the log law is presumed to describe the 3-D velocity. Chien and Wan [1999] investigated the physical mechanism of dividable flow regions and inferred that the mechanic energy in a 3-D flow may be transferred toward the near boundary, indicating that 3-D flows are dividable. Lundgren and Jonsson [1964] recognized that the concept "vertical depth" is a poor means for determining the boundary shear stress, velocity profile and diffusion coefficient, they alternatively used the "normal depth method" to divide the shallow, symmetric channel with a gentle varying bottom curvature. Chiu and Lin [1983] divided the flow field using a special curvilinear coordinate system composed of isovel curves and their normals. 
[4] Yang and Lim [1997, 1998, 2002] proposed the concept of "energy transportation through a minimum relative distance toward the nearest boundary". Essentially, the concept states the following.

[5] 1. For unit length in the streamwise direction, the surplus energy contained in any arbitrary flow volume will be transferred and dissipated over a unit area on the boundary. The direction of energy transportation is along the shortest geometrical distance, $\Psi$, between the location of the energy source concerned and the boundary.

[6] 2. The turbulent energy dissipation capacity of the boundary, D, has an indirect influence on the amount of surplus energy that will be transported from the flow field, and it depends on the characteristics of the boundary roughness.

[7] 3. Arising from points 1 and 2, it is hypothesized that the energy transportation is through a minimum relative distance, $\Phi$, such that

$$
\Phi=\Psi / \mathrm{D} \rightarrow \text { minimum }
$$

[8] 4. For a smooth boundary, $\mathrm{D}$ is scaled using the viscous length scale, $v / u_{*}$

$$
\mathrm{D}=\nu / \mathrm{u} *
$$

where $v=$ kinematic viscosity of fluid, and $\mathrm{u}_{*}=$ shear velocity. For a rough boundary, D is scaled using the boundary roughness height, $\Delta$,

$$
\mathrm{D}=\Delta
$$

[9] Thus the flow field can be divided into various subflow regions in accordance with the cross-sectional shape of the channel. Graf [1971] and Raudkivi [1976] expressed the boundary shear stress by multiplying the weight of the water in each subdivide area with energy slope, $\mathrm{S}$.

$$
\tau_{\mathrm{a}^{\prime} \mathrm{b}^{\prime}}=\lim _{\Delta \mathrm{p} \rightarrow 0} \rho \mathrm{gS} \frac{\Delta \mathrm{A}}{\Delta \mathrm{p}}
$$

where $\tau_{a^{\prime} b^{\prime}}=$ local shear stress on the elemental wetted perimeter $\Delta \mathrm{p}$ from point $\mathrm{a}^{\prime}$ to $\mathrm{b}^{\prime}, \Delta \mathrm{A}=$ area, $\rho=$ density of water and $\mathrm{g}=$ gravitational acceleration.

[10] The above mentioned concept states that the surplus energy is transported along the minimum normal line of boundary. However, in hydraulic engineering, the vertical distribution other than perpendicular direction of boundary plays a very important role in some cases, such as, diffusion equations of suspension or waste waters. The existing approaches are not sufficient to express this vertical characteristic of open channels with complex geometry. The objectives of this paper are to extend the concept proposed by Yang and Lim [1997], to express the vertical averaged shear stress and velocity in 3-D channels, and also to provide a simple model for estimating the important diffusion coefficients.

\section{General Description of Determining Depth-Averaged Reynolds Shear Stress}

[11] For a steady, uniform and fully developed channel flow, the mechanical energy in the shaded region of Figure 1 will be transferred toward the nearest boundary and dissipated along the wetted perimeter $\mathrm{a}^{\prime} \mathrm{b}^{\prime}$, according to Yang and

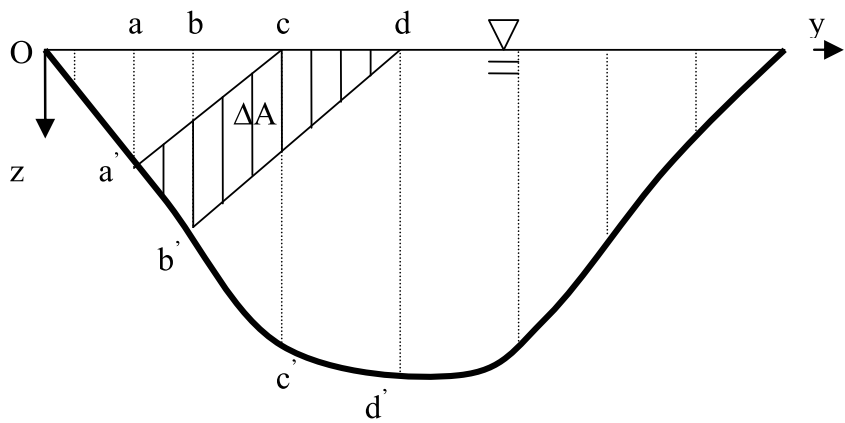

Figure 1. Hydraulic division line for channels with curved boundary.

Lim [1997]. Hence the local boundary shear stress may be assessed by equation (4) after the flow region is divided into many elements. Then, if only the isolated element "Oc' $c$ " in Figure 1 is discussed, and the gravitational component in the streamwise direction has to be balanced by the friction force on the boundary and the interface $\mathrm{cc}^{\prime}$, then the depthaveraged Reynolds shear stress $\bar{\tau}_{x y}$ can be determined using the following force balance equation:

$$
\rho g A_{O c c^{\prime}} S=\int_{0}^{c^{\prime}} \tau_{(p)} d p+h_{c} \bar{\tau}_{x y}
$$

or

$$
\bar{\tau}_{x y}=\rho g \mathrm{SA}_{\mathrm{Occ}^{\prime}} / \mathrm{h}_{\mathrm{c}}-\sum_{\mathrm{i}=1}^{\mathrm{n}} \tau_{\mathrm{i}} \mathrm{p}_{\mathrm{i}} / \mathrm{h}_{\mathrm{c}}
$$

where $\mathrm{A}_{O c c^{\prime}}=$ area of flow region $O c c^{\prime} ; \mathrm{h}_{\mathrm{c}}$ is the water depth at point $c ; \bar{\tau}_{x y}=$ depth-averaged apparent shear stress at the vertical interface $c c^{\prime}, \mathrm{p}=$ wetted perimeter, $\mathrm{n}=$ total element no.; $\tau_{\mathrm{i}}$ and $\mathrm{p}_{\mathrm{i}}$ are boundary shear stress and wetted perimeter in element i. Equation (6) may be useful in a numerical model.

[12] The depth-averaged apparent shear stress on a vertical interface, $\bar{\tau}_{x y}$ is expressed as

$$
\bar{\tau}_{x y}=\frac{1}{h} \int_{0}^{h}\left(-\rho \overline{u^{\prime} v^{\prime}}-\rho u v\right) d z
$$

where $-\rho \overline{u^{\prime} v^{\prime}}=$ Reynolds shear stress; $-\rho \mathbf{u v}=$ the lateral transport rate of momentum due to secondary currents that exhibits obvious influence on $\bar{\tau}_{x y}$ in meandering and nonstraight channels, $\mathrm{u}^{\prime}$ and $\mathrm{u}$ are turbulent and timeaveraged velocities in the streamwise direction and $\mathrm{v}^{\prime}$ and $\mathrm{v}$ in the lateral direction, respectively. In straight channels [Parker, 1978], Shiono and Knight [1988] assumed that this term of secondary flow was negligible.

[13] Equation (7) indicates that the apparent shear stress has two quite distinct components, one arising from secondary flows and the other from turbulence. Normally, these are lumped together into a single value of $\bar{\tau}_{x y}$ as done by Shiono and Knight [1991], Knight and Demetriou [1983], and Myers [1978].

[14] The prediction of diffusion in rivers generally requires an accurate treatment of lateral spreading that is characterized by the transverse turbulent diffusion coefficient, this coefficient is generally assumed to be identical with the eddy diffusivity $\mathrm{E}_{\mathrm{y}}$ [Shiono and Knight, 1991]. Thus one can link the lateral diffusion coefficient with the 


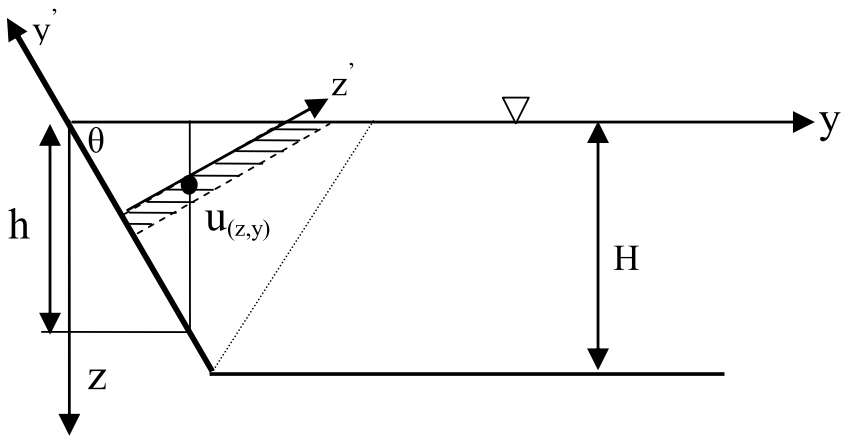

Figure 2. An open channel with a linear slope sidewall.

depth-averaged apparent shear stress and lateral depth mean velocity as follows

$$
\bar{\tau}_{x y}=\rho E_{y} \frac{d \bar{u}}{d y}
$$

the theoretical eddy viscosity $\mathrm{E}_{\mathrm{y}}$ in rivers can be obtained if the boundary shear stress and velocity distribution are known. It is apparent that the authors' method allows estimation of transverse diffusion coefficients by means of the assignment of boundary stress given in equations (5) and (6), this is because the depth-averaged apparent shear stress $\bar{\tau}_{x y}$ in equation (8) can be determined from the boundary shear stress using equation (5), and dū/dy can be determined from the depth-averaged velocity distribution.

\section{Lateral Depth-Averaged Apparent Shear Stress and Velocity in 3-D Flows}

\subsection{Rectangular and Trapezoidal Channels}

[15] For a straight river as shown in Figure 2, the following governing equation can be obtained by adding the continuity equation to the $\mathrm{x}$ direction momentum equation:

$$
\frac{\partial\left(\mathrm{uv}-\tau_{\mathrm{xy}} / \rho\right)}{\partial \mathrm{y}^{\prime}}+\frac{\partial\left(\mathrm{uw}-\tau_{\mathrm{xz}} / \rho\right)}{\partial \mathrm{z}^{\prime}}=\mathrm{gS}
$$

where $\mathrm{x}$ is defined as the streamwise direction; $\mathrm{z}^{\prime}$ is the direction normal to the boundary; $\mathrm{y}^{\prime}$ is the direction parallel to the boundary; $\mathrm{u}, \mathrm{v}$ and $\mathrm{w}$ are mean velocity in $\mathrm{x}, \mathrm{y}^{\prime}$ and $\mathrm{z}^{\prime}$ directions, respectively; $\mathrm{u}^{\prime}, \mathrm{v}^{\prime}, \mathrm{z}^{\prime}$ are turbulent fluctuating components, and $\tau_{\mathrm{xy}}=\mu \partial \mathrm{u} / \partial \mathrm{y}^{\prime}-\rho \overline{\mathrm{u}^{\prime} \mathrm{v}^{\prime}}$ and $\tau_{\mathrm{xz}}=\mu \partial \mathrm{u} / \partial \mathrm{z}^{\prime}-\rho \overline{\mathrm{u}^{\prime} \mathrm{w}^{\prime}}, \mu$ is dynamic viscosity, $\rho$ is fluid density.

[16] Yang and Lim [1997] showed that the boundary shear stress distribution can be determined using equation (4) because the surplus energy in the shaded element shown in Figure 2 will be transferred toward the nearest boundary, i.e.;

$$
\tau_{\mathrm{b}}=\rho \mathrm{gLS}
$$

where $\tau_{b}=$ local boundary shear stress; L is the height of shaded element shown in Figure 2, generally speaking $L$ is the normal distance from the boundary to the free surface or to the dotted division line that the relative distance to the side wall is equal to the distance to the bed [Yang, 1996]. For a channel with uniform roughness distribution, the division line shown in Figure 2 is consistent to the bisector of the base angle, and the boundary shear stress distributions measured by Ghosh and Roy [1970] are shown in Figure 3 with $\theta=63.4^{\circ}, 45^{\circ}$ to $30^{\circ}$. In Figure 3 the measured boundary shear stress is expressed using open cycles and the calculated shear stresses using equation (10) are represented by the solid lines. It can be seen that the proposed model provides a good agreement with the measured boundary shear stress in open channels. The depth-averaged apparent shear stress in the trapezoidal channel can be determined by substituting equation (10) into equation (5).

[17] As the energy is transported along the normal line of the boundary, the second term of equation (9) is negligible relative to the first term, hence equation (9) can be simplified as follows

$$
\frac{\partial\left(\mathrm{uw}-\tau_{\mathrm{xz}} / \rho\right)}{\partial \mathrm{z}^{\prime}}=\mathrm{gS}
$$

[18] As first approximation, we can ignore the influence of secondary currents. Then equation (11) becomes a quasi2-D momentum equation, next by introducing the mixing length theorem into equation (11), the velocity distribution
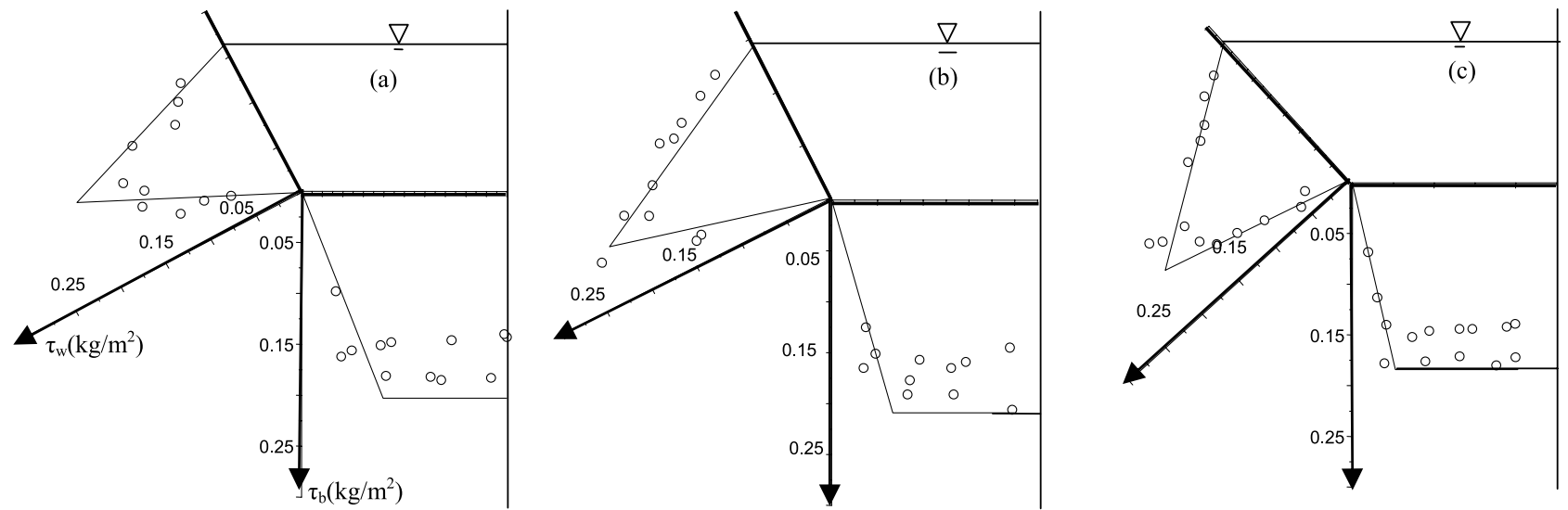

Figure 3. Comparison of measured boundary shear stress in trapezoidal channels with equation (10). 


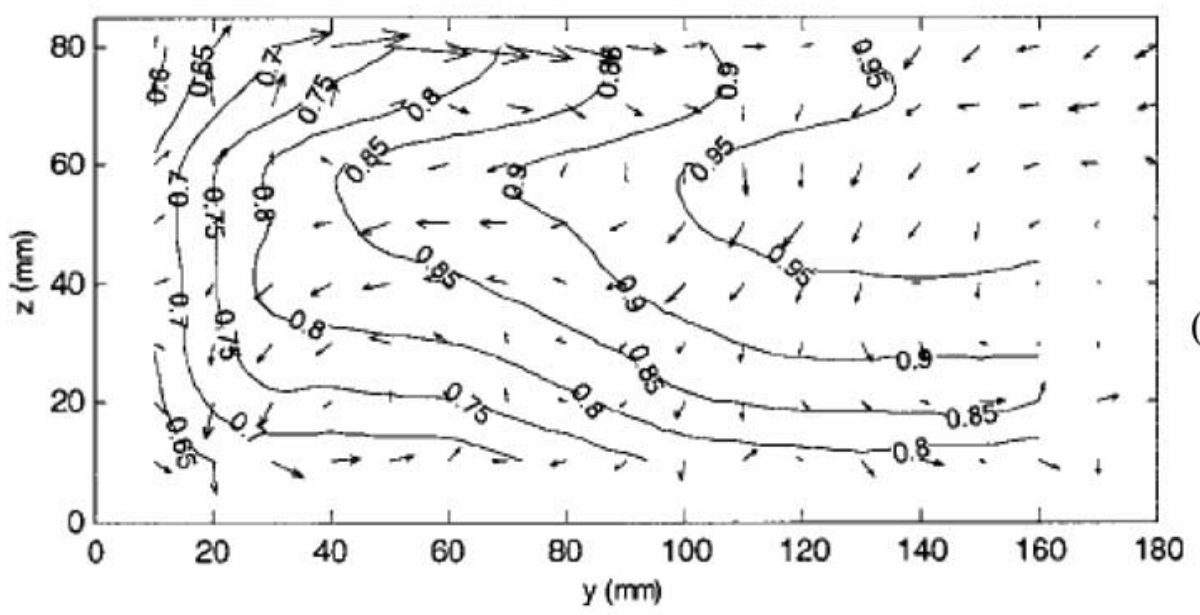

(a)

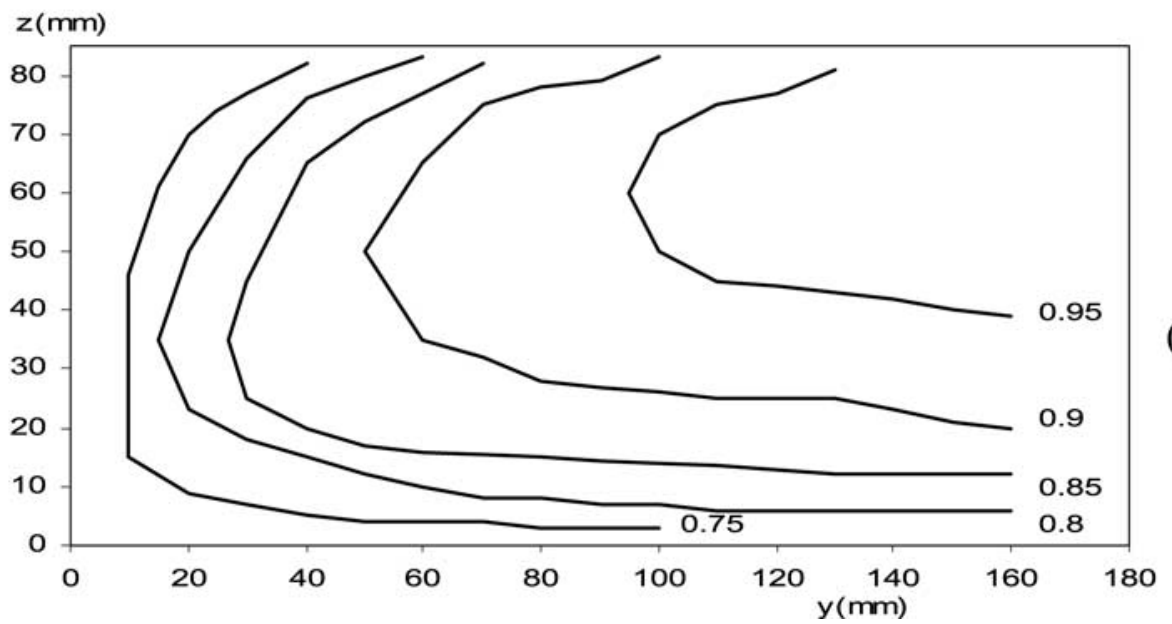

(b)

Figure 4. (a) Velocity contours (u/uo) measured by Shiono and Feng [2003]. (b) Calculated velocity contours (u/uo) using equation (13).

in the shaded stripe shown in Figure 2 can be expressed in the following form [Yang, 1996],

$$
\frac{\mathrm{u}_{\left(\mathrm{z}^{\prime}, \mathrm{y}^{\prime}\right)}}{\mathrm{u}_{*}}=2.5 \ln \left(\mathrm{f} \frac{\mathrm{z}^{\prime}}{\mathrm{z}_{\mathrm{o}}}\right)
$$

in which coefficient $\mathrm{u}_{*}$ is the overall mean shear velocity $=(\mathrm{gRS})^{0.5} ; \mathrm{f}=\mathrm{u}_{*(\mathrm{y})} / \mathrm{u}_{* 2 \mathrm{~d}} ; \mathrm{u}_{*(\mathrm{y})}$ is the local shear velocity determined from the local boundary shear stress, $\mathrm{u}_{* 2 \mathrm{~d}}$ is the shear velocity at the channel center $=$ $(\mathrm{gHS})^{0.5}$; for smooth boundary $\mathrm{z}_{\mathrm{o}}=\nu /\left(9 \mathrm{u}_{* 2 \mathrm{~d}}\right)$; for rough boundary $\mathrm{z}_{\mathrm{O}}=\Delta / 30$. Equation (12) indicates that the velocity is proportional to the logarithmic distance from the boundary, i.e., $\ln \left(z^{\prime}\right)$, the wall normal distance $z^{\prime}$ can be expressed as $(\mathrm{h}-\mathrm{z}) \cos \theta$ in the vertical and horizontal coordinate using the geometrical relationship provided in Figure 2.

[19] On the other hand, it is well known that in open channel flows, the maximum velocity often appears below the free surface (also termed as "dip phenomenon") due to the influence of secondary currents. Yang et al. [2004] examined well the measured velocity profiles in the literature and concluded that the difference between the measured velocity and the predicted value of log law can be repre- sented by the logarithmic distance from the free surface, i.e., $\ln (\mathrm{z})$. Thus the local point velocity $\mathrm{u}_{(\mathrm{y}, \mathrm{z})}$ can be determined in the following form:

$$
\frac{\mathrm{u}_{(\mathrm{z}, \mathrm{y})}}{\mathrm{u}_{*}}=2.5 \ln \left(\mathrm{f} \frac{\mathrm{h}-\mathrm{z}}{\mathrm{z}_{\mathrm{o}}} \cos \theta\right)+2.5 \alpha \ln \left(\frac{\mathrm{z}}{\mathrm{h}}\right)
$$

the second term of RHS in equation (13) is introduced to express the so called dip phenomenon. The coefficient $\alpha$ is empirically expressed as follows:

$$
\alpha=\frac{1.3}{\sin \theta} \exp \left(-\frac{\mathrm{y}}{\mathrm{H}}\right)
$$

Equations (13) and (14) include the influence of boundary and free surface.

[20] Figure 4a shows the experimental results of velocity contour measured by Shiono and Feng [2003] in a rectangular channel $(\sin \theta=1)$, the calculated velocity contours using equations (13) and (14) are shown in Figure 4b. The comparison in Figures $4 \mathrm{a}$ and $4 \mathrm{~b}$ shows that the proposed model gives a reasonable agreement with the experimental data. 


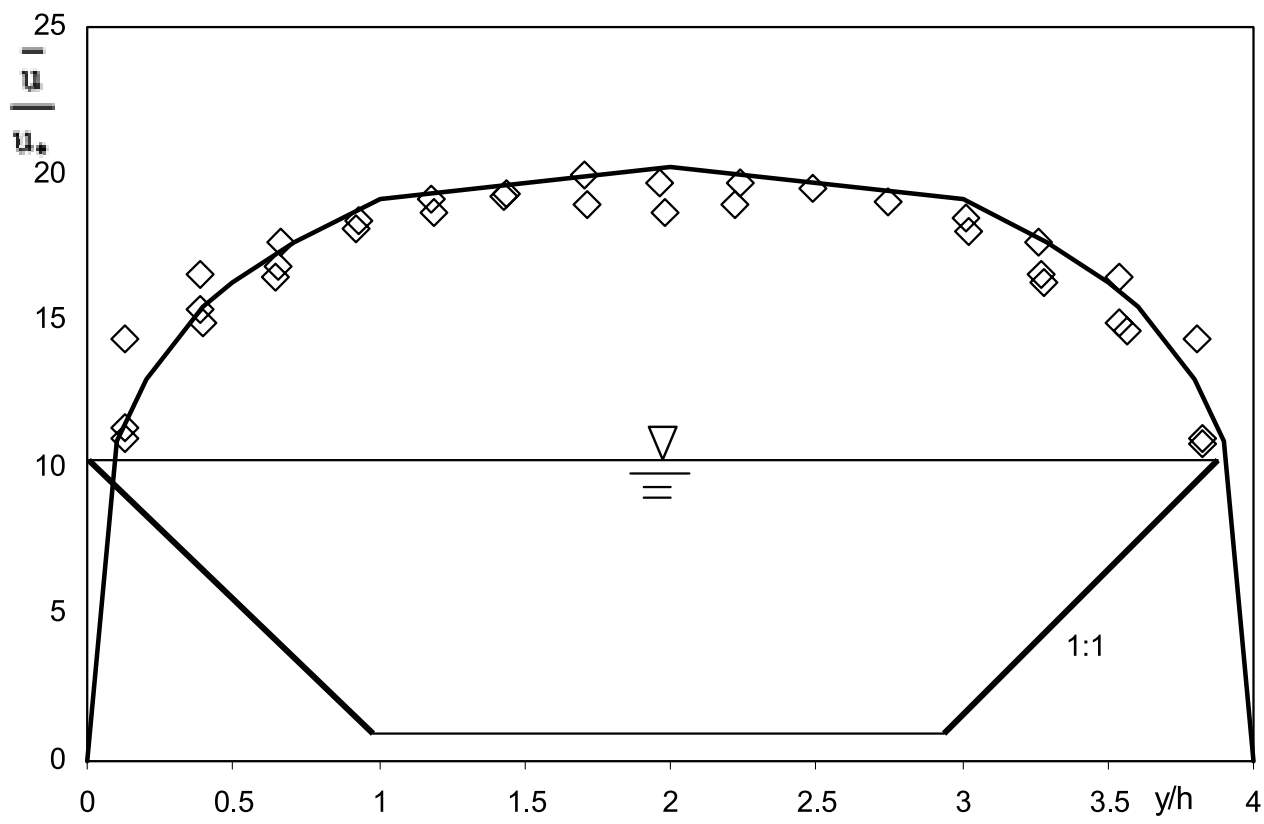

Figure 5. Comparison of depth-averaged velocity between equation (16) and measured data $\left(\theta=45^{\circ}\right)$.

[21] The depth-averaged velocity $\overline{\mathrm{u}}_{(\mathrm{y})}$ in the sidewall region of trapezoidal channel flows can be obtained by integrating equation (13) with respect to $\mathrm{z}$,

$$
\frac{\overline{\mathrm{u}}_{(\mathrm{y})}}{\mathrm{u}_{*}}=\frac{2.5}{\mathrm{~h}} \int_{0}^{\mathrm{h}} \ln \left(\mathrm{f} \frac{\mathrm{h}-\mathrm{z}}{\mathrm{z}_{\mathrm{o}}} \cos \theta\right) \mathrm{dz}-2.5 \alpha
$$

However, the theoretical integration of equation (15) in a trapezoidal channel is implicit because $u_{*(y)}$ in $f$ is a variable. To simplify the expression, it is assumed that the shear velocity $\mathrm{u}_{*(\mathrm{y})}$ in $\mathrm{f}$ can be replaced by the mean side wall or mean bed shear velocity, i.e., $\overline{\mathrm{u}}_{*_{\mathrm{w}}}$ and $\overline{\mathrm{u}}_{*_{\mathrm{b}}}$ in the region $\mathrm{z}<\mathrm{H} / \tan \theta$ and $\mathrm{z} \geq \mathrm{H} / \tan \theta$, respectively. Thus the depth-averaged velocity is expressed as

$$
\frac{\overline{\mathrm{u}}_{(\mathrm{y})}}{\mathrm{u}_{*}}=2.5 \ln \left(\mathrm{f} \frac{\mathrm{h}}{\mathrm{z}_{\mathrm{o}}} \cos \theta\right)-2.5(1+\alpha)
$$

Figure 5 compares the lateral distribution of depth-averaged velocity in a trapezoidal channel measured by Knight et al. [1993] with equation (16), and it shows that a good agreement is achieved.

\subsection{Compound Channels}

[22] Most natural rivers have floodplains that extend laterally away from the main river channel at a gentle gradient or in a series of terraces. There is always some discharge in the main channel all of the time, but the floodplains are dry most of the time except during times of flood when they perform a vital function. A number of experimental and numerical studies have been performed and a comprehensive review can be found in Shiono and Knight's [1991] work.

[23] The above mentioned concept states that the surplus energy is transported along the minimum normal line of boundary. Thus the local boundary shear stress can be determined using equation (10), Khodashenas and Paquier [1999] ascertained that the boundary shear stress distribu- tion in compound channel flows can be determined by the concept presented except any sharp convex change in the lateral slope, at which the boundary shear stress should be infinite according to equation (4), because at these sharp points, $\Delta \mathrm{A}$ bounded by two wall normal lines of boundary should be finite but corresponding wetted perimeter $\Delta \mathrm{p}$ should be zero. This location of sharp convex change is identified as point "e" in Figure 6.

[24] To smooth the boundary shear stress distribution at point "e," Khodashenas and Paquier [1999] suggested that the number of segments be subjectively limited to 20 to 50 . Yang and Lim [2002] pointed out that it is unreasonable if the boundary shear stress at the interface depends on number of segments. Alternatively, Prasad [2002] suggested that the bisector of angle "e" can be used as the division line like the division lines at "a" and "c," but he agreed that the local boundary shear stress near " $\mathrm{e}$ " cannot be calculated.

[25] The writers proposed an alternative method to calculate the boundary shear stress at the edge of flood plain shown in Figure 6, in which a circle with an empirical radius of $10 \mathrm{~h}_{1}$ is tangential to "ae" and "ec," the energy in the element bounded by two radiative lines from the circular center will be transferred to and dissipated on the point "e," then the local boundary shear stress can be determined by equation (4). Thus a continuous distribution of boundary shear stress can be obtained from "a" to "e" and from "e" to "c." Figure 7 shows the comparison of boundary shear stress between Shiono and Knight's [1991] experimental data and the simplified model. Similarly, the depth-averaged apparent shear stress can be computed in the compound channel when the local boundary shear stress is known.

[26] The main channel shown in Figure 6 is similar to a trapezoidal channel that the depth of interface is zero, and equation (16) can be used to assess the depth-averaged velocity when the hydraulic radius of the main channel is used for the calculation of shear velocity $\mathrm{u}_{*}$, the distance 


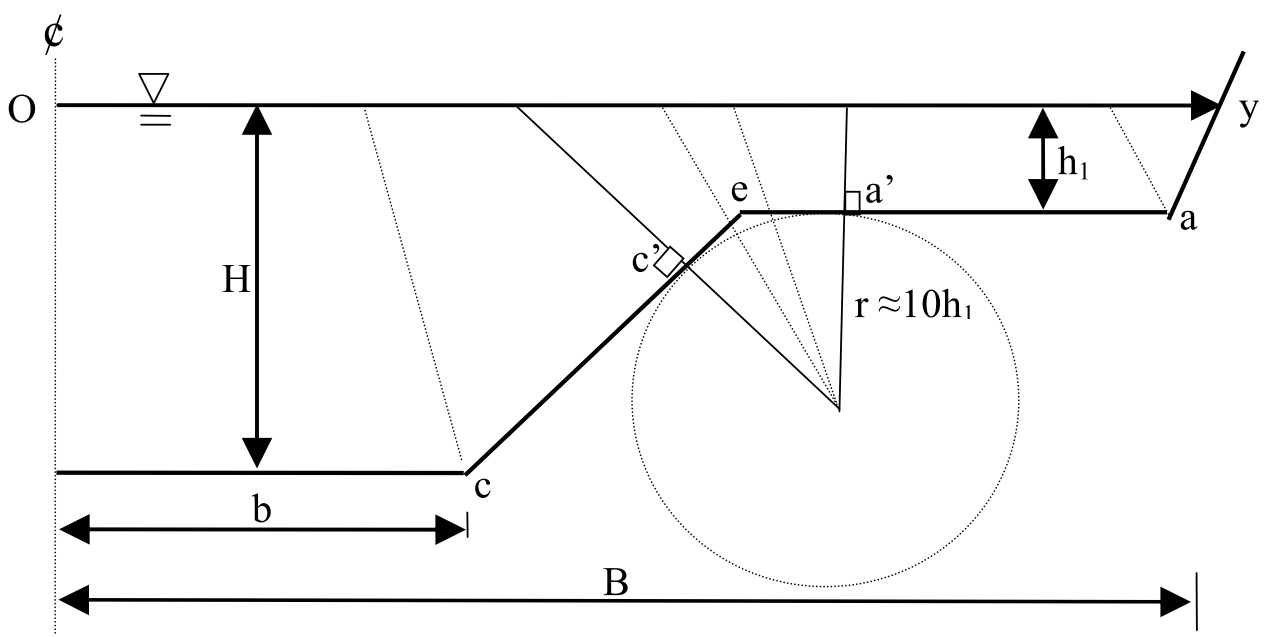

Figure 6. Cross section of a compound channel with notations.

from the interface is used to replace the variable $\mathrm{z}$ in equation (14).

[27] Similarly, the floodplain can be treated as another trapezoidal channel, and equations (14) and (16) can be used to assess the depth-averaged velocity when the floodplain's hydraulic radius is used for the determination of shear velocity $\mathrm{u}_{*}$, by equating velocities on both sides of the interface between the main channel and the floodplain, one can determine the coefficient in equation (14) instead of 1.3.

[28] Shiono and Knight [1991] measured the boundary shear stress and the depth-averaged velocity in compound channels, the geometrical parameters were $\mathrm{b}=0.75 \mathrm{~m} ; \mathrm{B}=$ $3.15 \mathrm{~m} ; \mathrm{H}-\mathrm{h}_{1}=0.15 \mathrm{~m}$, the slopes of main channel sidewall and the floodplain sidewall are 1:1. The measured water depths $\mathrm{H}$ were $0.169 \mathrm{~m}, 0.178 \mathrm{~m}, 0.187 \mathrm{~m}$ and $0.198 \mathrm{~m}$. The measured bed shear stress is shown in Figure 7.

[29] In Figure 7 the bed shear stress of main channel is similar to that in the trapezoidal channel shown, i.e., equal to $\rho \mathrm{gHS}$ in the central portion, then it gradually approaches to zero in the corner region for the shear is proportional to the vertical distance from the bed to the division line (see Figure 6). Thus there is a sharp inflection point in Figure 7 at point $\mathrm{c}$ of Figure 6. Along the slope from the main channel to the floodplain, the local boundary shear stress can be similarly determined by the normal distance from the boundary to the division line or the free surface except region near the singular point "e", i.e., "c ea'" shown in Figure 6 where the boundary shear stress can be smoothened using the above mentioned method, thus one avoids the infinite shear stress at point " $e$ ", hence another sharp point appears in Figure 7. The bed shear in the floodplain along "a' a" except the corner region can be assessed by $\rho \mathrm{gh}_{1} \mathrm{~S}$, the corner region of floodplain is exactly similar to the trapezoidal channel and the method of determining shear shown in Figure 3 can be applied.

[30] As shown in Figure 7, the discrepancy between the measured and modeled shears is noticeable. For example, the model shows that the shears at points "c" and "a" are zero because they are stagnant points, similar to the corner points of Figure 3, but the measurement is not zero at these points, this can be probably attributed to the measurement error. As for the discrepancy in other regions, further studies are needed to identify the cause. However, it should be mentioned that Khodashenas and Paquier [1999] compared the proposed concept with other methods including the vertical depth method (VDM) and vertical area method (VAM), and they concluded that the proposed concept yields the best agreement with measured data, they also found that the proposed concept gives infinite shear at the convex points (for example point e in Figure 6), this study improves Khodashenas and Paquier's [1999] suggestion for the determination of shear at the singular points.

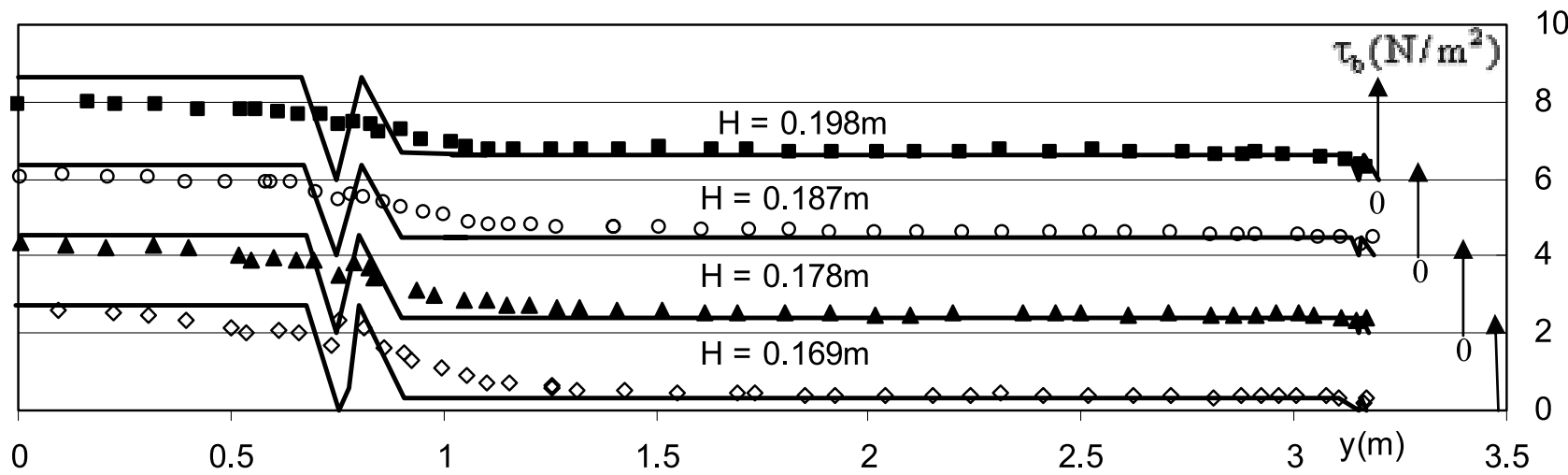

Figure 7. Comparison of measured and calculated boundary shear stresses in compound channels. 


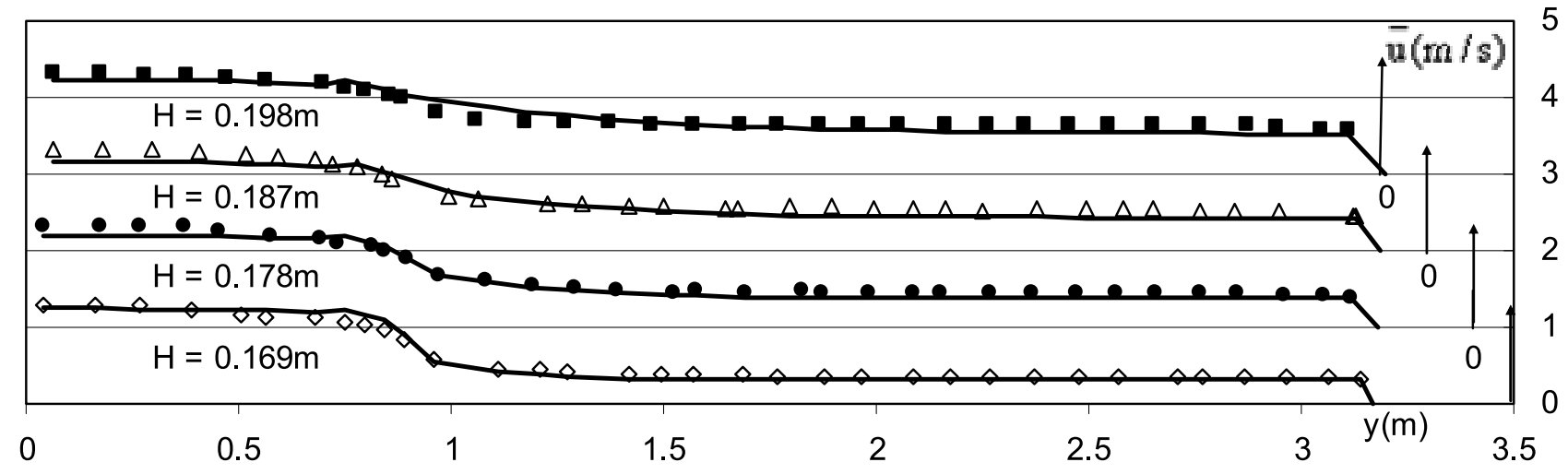

Figure 8. Comparison of measured and calculated depth-averaged velocity in compound channels.

[31] Shiono and Knight's [1991] measurement of depthaveraged velocity is shown in Figure 8. The calculated results are presented using solid lines, a good agreement with the measured data is achieved.

[32] The lateral diffusion coefficient, therefore can be determined using equation (8) with the knowledge of depth-averaged apparent shear stress and velocity. It is obvious that the proposed model avoids the requirement of coordinate transformation from the normal direction of boundary to vertical direction based on actual geometry. The coordinate transformation would be extremely difficult in some case, thus the proposed model makes this more tractable. However, it should be stressed that there are some errors that may occur, as discussed above when the model is applied to convex singular points. However, on the other hand, the boundary with sharp inflection points generally do not exist in the natural rivers or canals, thus the discrepancy shown in Figure 7 should not seriously impair the model's applicability in practice.

\section{Conclusions}

[33] Depth-averaged apparent shear stress and depth mean velocity are important parameters for the determination of diffusion coefficients in fluid dynamics and environmental engineering. A simple method for their predictions has been established. The approach is based on the concept of energy transportation through minimum relative distance developed by Yang and Lim [1997]. On the basis of this concept, the flow cross-sectional area in a channel can be divided and the boundary shear stress can be determined. The lateral distributions of the boundary shear stress in trapezoidal channels, compound channels are derived by taking the irregularity of channel shape into account. Thus the lateral depth-averaged apparent shear stress can be determined using equation (5) which is developed based on the force balance equation.

[34] The equation of local velocity distribution in open channels is proposed by taking the influence of the sidewalls and free surface into account, then the depth-averaged velocity is obtained. By comparing with experimental data in a trapezoidal channel it is found that the developed equations express the depth mean velocity well. Good agreements between the measured and calculated depthaveraged velocity in compound channel are also achieved. Thus, with the knowledge of depth-averaged apparent shear stress and depth-averaged velocity, one is able to assess the lateral diffusion coefficient using equation (8).

\section{Notation}

b width of channel bed.

D characteristic length representing the energy dissipation capacity of boundary.

$\mathrm{E}_{\mathrm{z}}$ transverse diffusion coefficient.

f a correction factor.

g gravitational acceleration.

$\mathrm{h}_{1}$ water depth in floodplain.

$\mathrm{H}$ water depth in main channel.

$\mathrm{p}$ parameter.

$\mathrm{S}$ energy slope.

$\mathrm{u}$ mean velocity.

$\mathrm{u}_{*}$ shear velocity.

$\mathrm{u}_{* 2 \mathrm{~d}} \quad$ shear velocity at channel central line.

$\bar{u}$ depth mean velocity.

$\mathrm{z}$ vertical distance from the bed.

$\mathrm{z}_{\mathrm{O}}$ datum height of velocity profile.

$\mathrm{y}$ distance.

$\rho$ density of water.

$\nu$ kinematic viscosity of fluid.

$\tau$ local shear stress.

$\tau_{\mathrm{b}}$ boundary shear stress.

$\bar{\tau}_{\mathrm{xz}}$ depth-averaged apparent shear stress.

$\Phi$ relative distance.

$\Psi$ geometrical distance.

$\Delta$ boundary roughness of boundary.

$\theta$ angle.

$\alpha$ coefficient.

\section{References}

Adachi, S. (1962), The effects of side walls in rectangular cross sectional channel (in Japanese), Trans. Jpn. Soc. Civ. Eng., 81, 17-26.

Chien, N., and Z. Wan (1999), Mechanics of Sediment Transport, Am. Soc. of Civ. Eng., Reston, Va.

Chiu, C. L., and G. F. Lin (1983), Computation of 3-D flow and shear in open channels, J. Hydraul. Div. Am. Soc. Civ. Eng., 109, 1424-1440.

Einstein, H. A. (1942), Formulas for the transportation of bed load, Trans. Am. Soc. Civ. Eng., 107, 133-169.

Ghosh, S. N., and N. Roy (1970), Boundary shear distribution in open channel flow, J. Hydraul. Div. Am. Soc. Civ. Eng., 96(4), 967-994.

Graf, W. H. (1971), Hydraulics of Sediment Transport, McGraw-Hill, New York.

Keulegan, C. H. (1938), Laws of turbulent flow in open channels, J. Res. Natl. Bur. Standards, 21, 707-740. 
Khodashenas, S. R., and A. Paquier (1999), A geometrical method for computing the distribution of boundary shear stress across irregular straight open channels, J. Hydrol. Res., 37(3), 381-388.

Knight, D. W., and J. D. Demetriou (1983), Floodplain and main channel flow interaction, J. Hydraul. Eng., 109, 1073-1092.

Knight, D. W., K. W. H. Yuen, and A. A. I. Alhamid (1993), Boundary shear stress distributions in open channel flow, in Physical Mechanisms of Mixing and Transport in the Environment, edited by K. Beven, P. Chatwin, and J. Millbank, pp. 51-87, John Wiley, Hoboken, N. J.

Lundgren, H., and I. G. Jonsson (1964), Shear and velocity distribution in shallow channels, J. Hydraul. Div. Am. Soc. Civ. Eng., 90(1), 1-21.

Myers, W. R. C. (1978), Momentum transfer in a compound channel, J. Hydraul. Res., 16, 139-150.

Parker, G. (1978), Self-formed straight rivers with equilibrium banks and mobile bed, J. Fluid Mech., 89(1), 127-146.

Prasad, B. V. R. (2002), A Geometrical method for computing the distribution of boundary shear stress across irregular straight open channels discussion, J. Hydraul. Res., 40(3), 535-542.

Raudkivi, A. J. (1976), Loose Boundary Hydraulics, 2nd ed., Pergamon, New York.

Shiono, K., and T. Feng (2003), Turbulence measurements of dye concentration and effects of secondary flow on distribution in open channel flows, J. Hydraul. Eng., 129(5), 373-384.

Shiono, K., and D. W. Knight (1988), Two dimensional analytical solution for a compound channel, paper presented at 3rd International Symposium on Refined Flow Modeling and Turbulence Measurements, Int. Assoc. for Hydraul. Res., Tokyo.

Shiono, K., and D. W. Knight (1991), Turbulent open-channel flows with variable depth across the channel, J. Fluid Mech., 222, 617-646.

Yang, S. Q. (1996), Interactions of boundary shear stress, velocity distribution and flow resistance in 3-D open channels, Ph.D. thesis, Nanyang Technol. Univ., Singapore.

Yang, S. Q., and S. Y. Lim (1997), Mechanism of energy transportation and turbulent flow in a 3-D channel, J. Hydraul. Eng., 123(8), 684-692.

Yang, S. Q., and S. Y. Lim (1998), Boundary shear stress distributions in smooth rectangular open channel flows, Proc. Inst. Civ. Eng. Water Maritime Eng., 130, 163-173.

Yang, S. Q., and S. Y. Lim (2002), A geometrical method for computing the distribution of boundary shear stress across irregular straight open channels discussion, J. Hydraul. Res., 40(3), 535-542.

Yang, S. Q., S. K. Tan, and S. Y. Lim (2004), Velocity distribution and dipphenomena in 3-D channels, J. Hydraul. Eng., in press.

Y.-Z. Wang and J.-X. Yu, School of Civil Engineering, Tianjing University, Tianjing 300072, China. (yzwang@public.tpt.tj.cn; yjx2000@eyou. com)

S.-Q. Yang, Maritime Research Center, Nanyang Technological University, 639798 Singapore. (csqyang@ntu.edu.sg) 